GUEST EDITORIAL

\title{
Asthma in South African children: Guidelines, obstacles and solutions
}

In this issue of CME, we continue the theme of paediatric asthma management that was commenced in the last edition. The prior articles, comprising the summary of the childhood asthma guidelines ${ }^{[1]}$ and the prevention of viral exacerbations of asthma, ${ }^{[2]}$ are followed here by articles on the diagnosis and management of asthma ${ }^{[3]}$ and the management of asthma exacerbations. ${ }^{[4]}$

The need for this update stems from recent major changes in the approach to the diagnosis and management of asthma. ${ }^{[5,6]}$ The most major of these changes stems from a renewed emphasis on the need to treat underlying asthma, in all grades of severity, with the 2019 Global Initiative for Asthma (GINA) guidelines ${ }^{[5]}$ that recommend that an inhaled corticosteroid (ICS) always be used in conjunction with a bronchodilator. This has led to an increasingly prominent role for ICS-formoterol single maintenance and reliever therapy. Data on safety and efficacy in children $<12$ years of age are still lacking, and therefore in children aged 6 - 11 years, regular low-dose ICS, or an ICS taken together with each dose of as-needed inhaled short-acting beta-2 agonist (SABA), is recommended as the first step in the revised GINA guidelines. ${ }^{[5]}$ The other major change has been the addition of ICS-tiotropium combination therapy as an option for the treatment of difficult-to-control asthma. This is recommended as a possible option for patients $\geq 6$ years at step 4 of the GINA guideline.

The adoption of guidelines into clinical practice is often fraught with practical difficulties. Adherence and control of asthma can be adversely affected by social and economic barriers, health system factors, patient-related factors, condition-related factors and treatment-related factors. ${ }^{[7]}$ Key treatment-related factors include the complexity of the regime, and the availability of medication and devices for its administration. Although the increasing adoption of long-acting beta-2 agonist (LABA)-formoterol combinations in the public health service is a step forward for more simpler regimes for the individual, the move toward LABA-formoterol regimes comes with its own challenges. Many practitioners, pharmacists and health administrators seem to be unaware of the different indications and uses of ICS-LABA combinations, depending on whether the LABA is formoterol or salmeterol. Whereas ICS-formoterol, with its quick onset of bronchodilator activity can be used as single maintenance and reliever therapy, ICS-salmeterol cannot. ${ }^{\left[{ }^{[3]}\right.}$ In addition, the techniques required to effectively use metered-dose inhalers and dry powder inhalers differ significantly, ${ }^{[9]}$ and training patients in the effective use of the devices is a critically neglected step of asthma control. Thus the availability of ICS-LABA combinations that comprise formulations with different LABA molecules and different delivery devices has the potential to lead to inappropriate prescribing and ineffective delivery.

These concerns call for a renewed focus on patient education and the availability of spacer devices throughout all levels of the health service. The key patient-education arm of the Allergy Society of South Africa (SA) is the Allergy Foundation of SA (AFSA). ${ }^{[10]}$ In addition to providing patient educational materials, the Allergy Foundation runs advanced masterclasses for doctors, pharmacists and nurses on various aspects of allergy management, including atopic dermatitis, urticaria, rhinitis, asthma, food allergy and anaphylaxis. AFSA has also recently partnered with Polyoak and Impulse Biomedical to produce a low-cost bottle spacer dubbed the AfriSpacer. Low-cost spacers have been shown to be as effective as commercial spacers for improving oxygen saturation, peak flow rates and clinical scores while reducing the need for additional treatment, and hospital admissions. ${ }^{[11,12]}$ During 2020 and early 2021, AFSA donated 100000 spacers to the provincial health departments of the Eastern Cape, Gauteng, KwaZulu-Natal, North West and Western Cape Provinces with funds obtained from ELMA Philanthropies. AFSA has now obtained funding from the Grundfos foundation to ensure the commercialisation and long-term availability of low-cost spacers in order to make them far more widely available.

This guideline, along with education, medication availability and provision of delivery devices, will promote care for many children, and hopefully lead to better control, better quality of life and lower healthcare expenditure.

\section{E Levin}

Division of Paediatric Allergy, Department of Paediatrics and Child Health, Faculty of Health Sciences, University of Cape Town, South Africa

michael.levin@uct.ac.za

1. Manjra AI, van Niekerk A, White DA, et al. Summary of childhood asthma guidelines, 2021: A consensus document. S Afr Med J 2021;111(5):395-399. https://doi.org/10.7196/SAMJ.2021. v111i5.15703

2. Green RJ. Viral infections, COVID-19 and asthma: Preventing viral exacerbations of asthma. S Aft Med J 2021;111(5):400-401. https://doi.org/10.7196/SAMJ.2021.v111i5.15707

Van Niekerk A. Childhood asthma: A best-practice strategy for diagnosis and assessment of control in South Africa. S Afr Med J 2021;111(8):23-27. https://doi.org/10.7196/SAMJ.2021.v111i5.15851

Kling S, White DA. Management of asthma exacerbations in children. S Afr Med J 2021;111(8):27-30 Kling S, White DA. Management of asthma exace
https://doi.org/10.7196/SAMI.2021.v111i5.15853

Global Initiative for Asthma. Global strategy for asthma management and prevention (updated 2019). Fontana-on-Geneva Lake, Wisc.: GINA, 2019. https://ginasthma.org/wp-content/uploads/2019/06/ Fontana-on-Geneva Lake, Wisc.: GINA, 2019. https://ginasthma.org/wp-content/uploads/2019/0 GINA-2019-main-report-June-2019-wms.pdf (accessed 20 March 2020).

6. Reddel HK, FitzGerald JM, Bateman ED, et al. GINA 2019: A fundamental change in asthma management: Treatment of asthma with short-acting bronchodilators alone is no longer recommended for adults and adolescents. Eur Respir J 2019;27;53(6):1901046. https://do org/10.1183/13993003.01046-2019

Zar HJ, Levin ME. Challenges in treating pediatric asthma in developing countries. Pediatr Drug 2012;14(6):353-359. https://doi.org/10.2165/11597420-000000000-00000

Levin ME. Combination of inhaled steroid and long-acting beta- 2 agonist therapy: Use and limitations. Curr Allerg Clin Immunol 2012;25(2):72-75

. Levin ME. Optimal aerosol delivery. Curr Allerg Clin Immunol 2011;24(1):27-30.

10. Allergy Foundation of South Africa. https://www.allergyfoundation.co.za/ (accessed 20 April 2021).

11. Zar HJ, Streun S, Levin M, Weinberg EG, Swingler GH. Randomised controlled trial of the efficacy of a metered dose inhaler with bottle spacer for bronchodilator treatment in acute lower airway of a metered dose inhaler with bottle spacer for bronchodilator treatment in acute lower

12. Rodriguez-Martinez C, Sossa M, Lozano JM. Commercial versus home-made spacers in delivering Rodriguez-Martinez C, Sossa M, Lozano JM. Commercial versus home-made spacers in delivering
bronchodilator therapy for acute therapy in children. Cochrane Database Syst Rev 2008;2:CD005536. bronchodilator therapy for acute therapy in children.
https://doi.org/10.1002/14651858.CD005536.pub2

S Afr Med J 2021;111(8):704. https://doi.org/10.7196/SAMJ.2021.v111i5.15855 